\title{
DIAGNÓSTICO AMBIENTAL NO CONTEXTO DA PAISAGEM DE FRAGMENTOS FLORESTAIS NATURAIS “IPUCAS" NO MUNICÍPIO DE LAGOA DA CONFUSÃO, TOCANTINS ${ }^{1}$
}

\author{
Iracy Coelho de Menezes Martins², Vicente Paulo Soares ${ }^{3}$, Elias Silva ${ }^{3}$ e Ricardo Seixas Brites ${ }^{4}$
}

\begin{abstract}
RESUMO - Este estudo foi conduzido em uma área localizada no município de Lagoa da Confusão, Estado do Tocantins, com os objetivos de diagnosticar fragmentos florestais naturais, denominados regionalmente de "ipucas", e mapear as diferentes feições fisionômicas e o uso antrópico da área. Para realização deste estudo utilizou-se um sistema de informações geográficas, IDRISI 2.0. O principal resultado obtido foi o histórico de perturbação que se intensificou a partir da criação do Estado do Tocantins e da implantação do Projeto Rio Formoso para o cultivo de arroz irrigado; em relação à classificação fisionômica e ao uso antrópico foram individualizadas 73 "ipucas". A partir das variáveis consideradas verificou-se que, em relação à área, 56,16\% dos fragmentos possuem áreas de até 5,00 ha e apenas quatro apresentaram áreas superiores a 100,00 ha. Aproximadamente 50\% destas possuem formas alongadas, o que indica alta relação perímetro/área. Apenas três "ipucas" apresentaram índice de circularidade (C) próximo de 1. Foram identificadas oito feições circunvizinhas às "ipucas". Destas, cinco são ambientes naturais (varjão-sujo, varjão-limpo, pastagem natural, corpos d'água e afloramento rochoso) e as demais resultantes de ações antrópicas (área agrícola, pastagem plantada e rede viária).
\end{abstract}

Palavras-chave: Fragmentos florestais, sensoriamento remoto e sistema de informações geográficas (SIG).

\section{ENVIRONMENTAL DIAGNOSIS WITHIN THE LANDSCAPE CONTEXT OF “IPUCA” NATURAL FOREST FRAGMENTS AT THE COUNTY LAGOA DA CONFUSÃO, TOCANTINS - BRASIL}

\begin{abstract}
This study was carried out at the county Lagoa da Confusão, Tocantins, Brasil, aiming to diagnose natural forest fragments, denominated "ipucas", as well as to map different phytophysiognomic features and anthropic land uses. The basic tool used was a Geographic Information System (GIS - IDRISI 2.0 for Windows). The main results achieved were: the disturbance history of the region increased after creation of the state of Tocantins and the implementation of the Rio Formoso rice crop project; 11 cover types were identified and mapped in the area; seventy three "ipuca" natural forest fragments could be individualized and mapped, being 56\% smaller than 5.00 ha and only four greater than 100.00; about 50\% of these fragments have elongated shape, indicating a high perimeter/ area relationship, while only three presented a circularity index close to 1.00; eight neighborhood types were identified, with five from natural environments and three resulting from anthropic effects.
\end{abstract}

Key words: $\quad$ Forest fragments, remote sensing, and geographic information system (GIS).

\section{INTRODUÇÃO}

O processo de expansão da fronteira agropecuária nas últimas décadas, especialmente na Região Norte do País, tem resultado em uma crescente fragmentação das florestas nativas. Essas atividades são fontes potenciais de distúrbios sobre o meio ambiente, fundamentalmente quanto às modificações de elementos componentes da estrutura física dos ecossistemas e da paisagem como um todo (Valério Filho, 1995).

1 Recebido para publicação em 18.4.2000.

Aceito para publicação em 20.6.2002.

2 Universidade de Palmas - 77065-240 Palmas-TO. ${ }^{3}$ Departamento de Engenharia Florestal da Universidade Federal de Viçosa - UFV. ${ }^{4}$ Ministério do Meio Ambiente/SDS, 71675-000 Brasília-DF. 
Nesse contexto, Viana (1990) definiu um fragmento florestal como uma área de vegetação natural, interrompida por barreiras antrópicas (estradas, povoados, culturas agrícolas, pastagens etc.) ou por barreiras naturais (montanhas, lagos, outras formações vegetais etc.) capazes de diminuir significativamente o fluxo de animais, pólen ou sementes.

Para Goosem (1997), há também o processo da "fragmentação interna", quando alguma atividade antrópica provoca a disjunção e o isolamento de áreas de vegetação nativa.

Dentre as conseqüências mais importantes do processo de fragmentação florestal, destacam-se a diminuição da diversidade biológica, o distúrbio do regime hidrológico das bacias hidrográficas, as mudanças climáticas, a degradação dos recursos naturais e a deterioração da qualidade de vida das populações tradicionais (Viana, 1990). Além disto, a fragmentação resulta em remanescentes de vegetação nativa que se avizinham a usos agrícolas e a outras formas de uso, e como resultado o fluxo de radiação, a água e os nutrientes dos solos são alterados significativamente (Saunders et al., 1991).

Assim, deve-se ressaltar a importância de planejar e monitorar o processo de fragmentação, principalmente em regiões que se encontram em estádios iniciais do processo de expansão agropecuária, como o caso da Região Norte do Brasil, especificamente o Estado do Tocantins.

A área em apreço foi escolhida para estudo das “ipucas", em virtude de este importante ecossistema representar grande potencial produtivo no Estado do Tocantins. Além disto, com a identificação dos principais parâmetros que definem as condições presentes, esperase alcançar recomendações que passem a ser extrapoladas para outras áreas semelhantes.

Considerando a importância de conhecer os parâmetros como histórico de perturbação, área, perímetro, forma e vizinhança como subsídios ao diagnóstico e à prescrição de técnicas de manejo, contemplou-se neste estudo o seguinte objetivo: realizar o diagnóstico ambiental no contexto da paisagem de fragmentos florestais naturais, conhecidos regionalmente como "ipucas", nas áreas do projeto agrícola e naquelas localizadas nos varjões, onde as atividades antrópicas são ainda de caráter indireto, ou seja, onde os projetos agrícolas e a pastagem ainda não foram implantados.

\section{MATERIAL E MÉTODOS}

\subsection{Caracterização da Área de Estudo}

A área de estudo ocupa um polígono de aproximadamente 8.000 ha, inserido na fazenda Lago Verde, município de Lagoa da Confusão, Estado do Tocantins, entre as coordenadas aproximadas UTM 643586 e 644060 leste e 8792795 e 8799167 norte, Zona 22 (Figura 1). A referida fazenda situa-se em uma faixa de ecótono entre o Cerrado e a Floresta Amazônica, nas proximidades da Ilha do Bananal. A região apresenta clima quente semi-úmido, com quatro a cinco meses secos (de maio a outubro). A temperatura média anual se mantém em torno de $24{ }^{\circ} \mathrm{C}$ (Brasil, 1994). O total pluviométrico anual situa-se em torno de $1.750 \mathrm{~mm}$, concentrados entre outubro e abril. A umidade relativa é considerada alta, variando entre 80 e $85 \%$ (Brasil, 1994). A região constitui uma extensa planície, formada por sedimentos quaternários fluviais, periodicamente inundados pelas cheias dos rios da região (Brasil, 1994). De modo geral, a unidade morfológica da região é caraterizada por uma planície fluviolacustre, com inúmeros lagos, lagoas e canais intermitentes com padrão de drenagem anastamosado (Brasil, 1981b). O relevo da região é praticamente plano em toda a sua extensão, com pouquíssimos morros residuais isolados (Mileski, 1994). Alguns pontos possuem cotas mais elevadas, em média 200 m (Brasil, 1994). Após a realização dos procedimentos analíticos verificou-se que as características dos solos das "ipucas" são: a) os solos, tanto no interior quanto nas bordas, são pouco profundos e apresentam os horizontes A e B; b) eles estão sobre grande influência do lençol freático próximo à superfície; e c) suas camadas superficiais, principalmente no interior do fragmento, apresentam alto grau de umidade e espessa camada de matéria orgânica. Os resultados da análise de granulometria tendem a mostrar que os eventos responsáveis pela formação das camadas sedimentares foram comandados por invasão de águas, transitando em distâncias relativamente grandes (demonstrada pela predominância de materiais finos, silte e argila), paralisadas pela presença de depressões no terreno e aí permanecendo o tempo suficiente para deposição de argila e silte, processo este correlacionado com as enchentes anuais. É observada a deposição anual relativamente pouco espessa, num processo repetitivo que demandou muitos anos, a julgar pelo grande tempo de residência dos processos hidromórficos no horizonte pretérito $\mathrm{B}_{3}$ pl $(79-113 \mathrm{~cm})$. Este horizonte, diferentemente dos 
demais superficiais (B), exprime bem as características plínticas e a cor cinza-brunada. O perfil da borda da "ipuca" mostra haver contribuição lateral (representada pelo teor de areia fina), além de seus resultados analíticos ( $\mathrm{Ca}, \mathrm{Mg}, \mathrm{Al}$ e $\mathrm{K}$ ) terem sido bastante diferentes daqueles dos demais horizontes. A granulometria do horizonte superficial do interior da "ipuca" amostrada $\left(\mathrm{A}_{1} 0-16 \mathrm{~cm}\right)$ evidencia uma contribuição lateral das terras circunvizinhas e, ou, mudanças na carga sólida da bacia de inundação (teor de areia grossa).

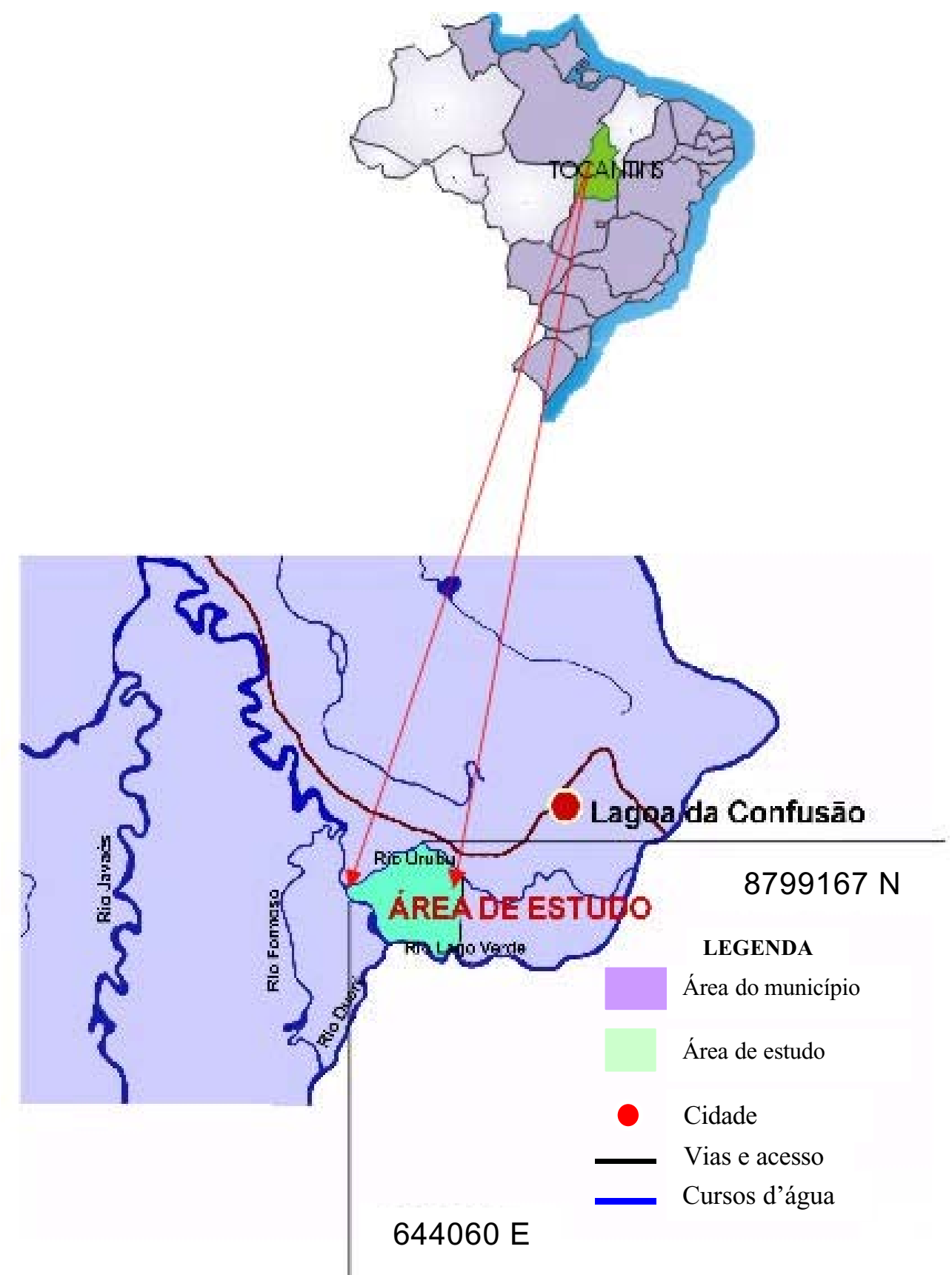

Figura 1 - Localização geográfica da área de estudo.

Figure 1 - Geographic location of the study area. 
A região possui uma rede de drenagem formada por rios de médio a grande porte, inúmeras nascentes e vários lagos, sendo esses navegáveis durante o ano todo (Brasil, 1981b; 1994). Uma característica marcante da drenagem da região é a presença das "ipucas", que no período de cheias fazem a ligação entre os vários rios, córregos e lagoas. Nessa época, os rios extrapolam seu leito normal, provocando inundações por toda a região (Brasil, 1994).

De acordo com Brasil (1994), na região predominam os campos, aparecendo fragmentos de cerrado e, ou, cerradões, matas ciliares e, em algumas partes, outras formações florestais na forma de ilhas. As formações campestres, conhecidas na região pelo nome de "varjões", estão localizadas nas partes mais baixas e são totalmente inundadas pelas cheias dos rios durante o período das chuvas. Nas cotas mais elevadas surgem formações vegetais típicas de mata seca, cerradão e cerrado. Destacamse ainda as formações conhecidas por "monchões" ou "murundus", caracterizados por apresentarem espécies típicas do complexo cerrado/cerradão, circundados pelos varjões.

\subsection{Métodos}

Considerando que não existem estudos científicos detalhados referentes a essa área, optou-se por fazer o Mapa de Classificação Fisionômica e Uso Antrópico da área, com o objetivo de facilitar as discussões referentes aos parâmetros considerados neste estudo. De posse dos resultados da classificação preliminar, realizada através de interpretação visual de uma imagem de satélite TM/ Landsat-5, bandas 3, 4 e 5, formato analógico, partiu-se para a primeira etapa de campo, ou seja, percorreu-se a área, visando confirmar a fidedignidade das informações obtidas da interpretação preliminar, por meio da coleta das amostras de treinamento para confirmação das diferentes feições fisionômicas e dos Pontos de Controle no Terreno - PCTs, para o georreferenciamento da imagem de satélite digital, através do GPS (Global Positioning System).

Para coleta das informações sobre o processo de ocupação da área, ou seja, dos históricos de perturbação nos diferentes níveis de antropização detectados, foram realizadas cinco entrevistas com pessoas moradoras da região, visto que na época a população da referida fazenda era de pouco mais de dez pessoas. A entrevista foi realizada de maneira informal e referiu-se, principalmente, ao tipo de uso, à época das primeiras atividades desenvolvidas e às formas de uso atual.

R. Árvore, Viçosa-MG, v.26, n.3, p.299-309, 2002
De posse das informações de campo passou-se para os procedimentos de georreferenciamento da imagem digital - Landsat-5 (Thematic mapper), órbita 223, ponto 68, quadrante B, obtida em 2 de julho de 1998, por meio da coleta dos PCTs, em campo, e da elaboração do mapa final de classificação fitofisionômica e uso antrópico. A elaboração dos mapas e a interpretação dos dados foram feitas a partir das composições coloridas 2, 3 e 4 (2B 3G e $4 \mathrm{R})$ e 3,4 e 5 ( $3 \mathrm{~B}, 4 \mathrm{G}$ e $5 \mathrm{R})$, da imagem de satélite $\mathrm{TM} /$ Landsat -5 , formato digital, através do aplicativo CartaLinx, método da interpretação visual em tela do computador. A opção para escolha das duas composições justifica-se pela resposta espectral, nas quais: na composição 2, 3 e 4 as "ipucas" ficaram com uma coloração mais facilmente reconhecível. Entretanto, as demais feições destacaram-se melhor na composição 3,4 e 5 . O percurso na área se deu de forma arbitrária, com ou sem o uso de veículos motorizados (tratores), por se tratar de uma área com poucas vias de acesso. Foi confirmada a existência de 11 classes de uso, sendo oito referentes às diferentes feições fisionômicas e três ao uso antrópico, quais sejam: "ipucas”, varjão-sujo, varjão-limpo, floresta ciliar, cerrado, pastagem nativa, pastagem plantada, área agrícola, corpos d'água, afloramento rochoso e rede viária.

Para análise e modelagem das informações armazenadas, visando a individualização das "ipucas" e, conseqüentemente, a obtenção dos parâmetros, como área, perímetro forma e vizinhança, em nível de paisagem dos referidos fragmentos, objeto central deste estudo, necessitou-se de vários módulos existentes no ambiente IDRISI.

As operações realizadas nos módulos dos aplicativos utilizados neste estudo estão apresentadas no fluxograma metodológico (Figura 2). Entretanto, em conseqüência do grande número de informações geradas (aproximadamente 700 arquivos, entre documentos e imagens) optou-se por usar um macro, para que os resultados pudessem ser mais rapidamente apresentados. Primeiramente, georreferenciou-se a imagem através do uso de PCTs (Pontos de Controle no Terreno), obtidos em campo com o GPS. Em seguida, procedeu-se à elaboração do Mapa de Classificação Fitofisionômica e Uso Antrópico. De pose do Mapa Final de Classificação Fisionômica e Uso Antrópico, individualizaram-se as "ipucas", criando um mapa booleano, em que para as "ipucas" foi atribuído o valor 1 e para as demais feições, zero. Com a obtenção do mapa com "ipucas", buscaram-se os resultados referentes aos parâmetros previamente definidos, utilizando para isto os módulos do aplicativo IDRISI 2.0 disponíveis, 

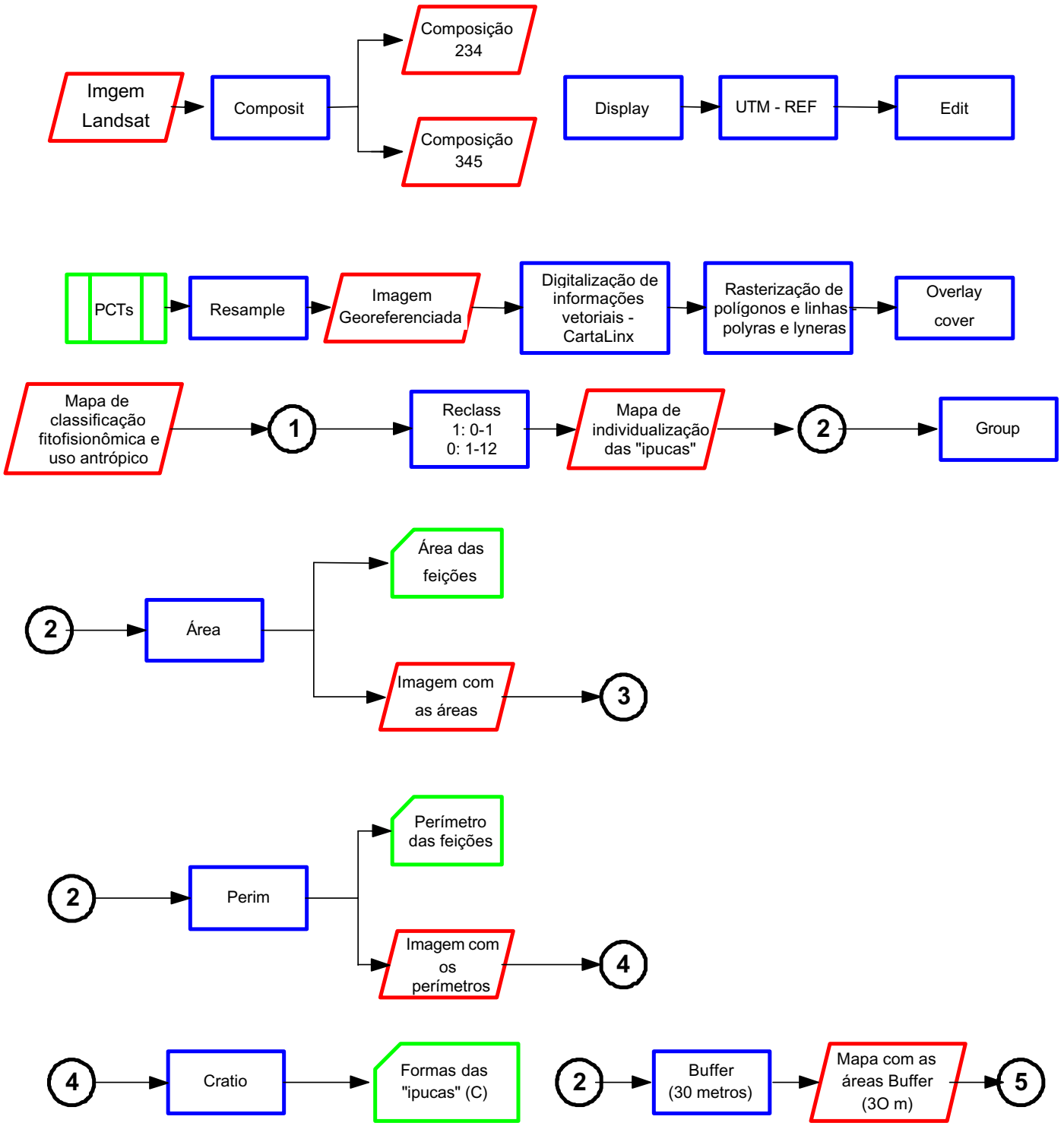

1

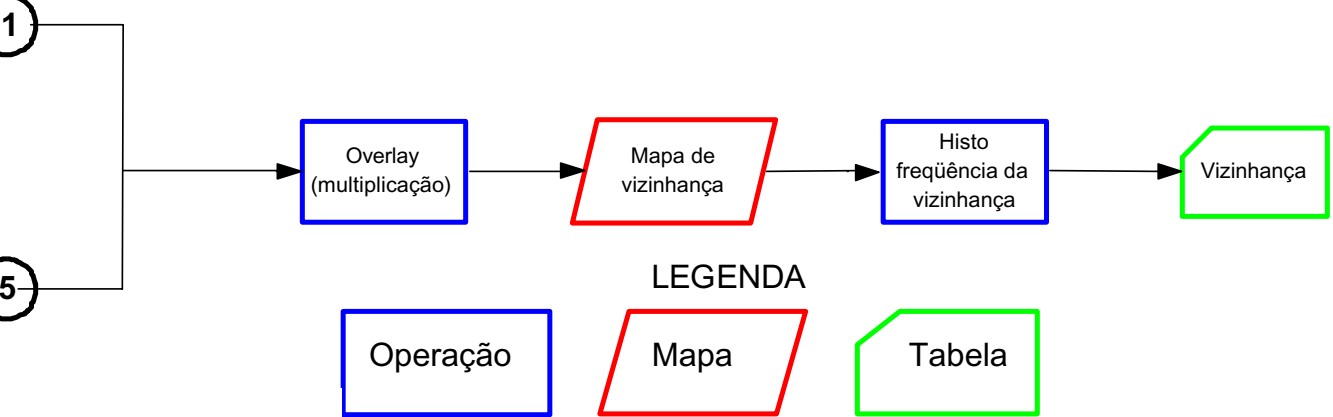

Figura 2 - Fluxograma metodológico das atividades realizadas através do sistema de informações geográficas.

Figure 2 - Flowchart showing the metodology using Idrisi version 2.0. 
sendo estes: para o cálculo das áreas o módulo utilizado foi o Area, que apresentou resultados em forma tabular, assim como o perímetro (Módulo Perim) e a forma (Módulo Cratio). Para a vizinhança foi feito um overlay de multiplicação, e em seguida, através do Modulo Histo, obtevese a freqüência da vizinhança em termos porcentuais.

Por meio do índice de circularidade ou da relação borda/interior, pode-se determinar a tendência em relação à forma de um fragmento. $\mathrm{O}$ fragmento apresentará tendência à forma arredondada, quando o valor do índice de circularidade (C) for próximo de 1. À medida que este se distancia de 1, tem-se um fragmento alongado.

\section{RESULTADOS E DISCUSSÃO}

\subsection{Classificação Fitofisionômica e Uso Antrópico}

O Mapa de Classificação Fisionômica e Uso Antrópico apresentou 11 classes, conforme apresentados na Figura 3. Por meio desta classificação, foram obtidas as feições varjão-limpo e sujo, ambas totalizando 3.003,75, sendo estas as que apresentaram as maiores contribuições na composição da paisagem. Desta forma, quando as demais feições de ocorrência natural são incluídas, como "ipucas" (1.107,36 ha), floresta ciliar (622,08 ha), cerrado (1.218,24 ha), pastagem natural (166,68 ha), corpos d'água (144,63 ha) e afloramento rochoso (376,65 ha), tem-se um ambiente menos alterado pelas ações antrópicas. Do total da propriedade (aproximadamente $8.000,00$ ha), a área aberta para o projeto agrícola, somada às áreas de pastagem plantada e vias de acesso, chega a aproximadamente $2.500,00$ ha, ou seja, pouco mais de $30 \%$ do total da propriedade foi substituída por atividades antropogênicas.

\subsection{Fatores Considerados}

Como resultados relacionados ao diagnóstico ambiental das "ipucas", no contexto da paisagem, foram obtidos os seguintes parâmetros: histórico de perturbação, área (tamanho), perímetro, forma e tipos de vizinhança.

\subsubsection{Histórico de Perturbação}

Por meio de informações obtidas em entrevistas com os moradores da região, levantou-se o histórico de perturbação da área.

Na região, o processo de ocupação iniciou-se no século passado, sendo as principais atividades econômicas a pecuária extensiva e as culturas agrícolas. Do total da propriedade, 96,00 ha de vegetação natural já haviam sido removidos quando da aquisição do imóvel, há dez anos, sendo esta destinada ao plantio de produtos para subsistência. Após a criação do Estado do Tocantins, grandes extensões de áreas foram submetidas à remoção da cobertura vegetal para plantio de espécies graminóides e cultivo de produtos como arroz, soja, melancia e outros.

Nos últimos anos, a agricultura tem atingido proporções em grande escala, podendo ser citado o Projeto Rio Formoso, que compreende uma área em torno de $100.000,00$ ha e que vem sendo utilizada para lavouras, principalmente de arroz irrigado. Para tal, são construídos reservatórios por barramento dos rios, destinados ao fornecimento de água, sendo estes os depositários finais de sedimentos, fertilizantes e agrotóxicos provenientes das áreas circunvizinhas aos recursos hídricos.

No processo de remoção da cobertura vegetal são utilizados tratores, nos quais se fixam "correntões", e em seguida essa cobertura é queimada, o que implica o não ou o subaproveitamento da madeira. Quando estas são aproveitadas, em geral são destinadas à produção de carvão vegetal ou para uso doméstico.

Um fato relevante é a inexistência ou deficiência de cercas que impeçam o acesso do rebanho bovino para o interior das áreas remanescentes (“ipucas"). Além deste, chama a atenção a rede viária, destinada ao acesso de máquinas e veículos motorizados para o preparo da terra e escoamento da produção agrícola.

Em conseqüência da baixa altitude da área, aproximadamente $180 \mathrm{~m}$, e por permanecer temporariamente submersa pelas águas pluviais (entre quatro e cinco meses), os aterros de acesso são construídos em nível superior, em torno de 4 a $5 \mathrm{~m}$. Isto implica a entrada de material carreado de outras localidades, sendo estes estranhos ao ambiente. Ainda com referência à construção destas, chama a atenção o fato de muitas "ipucas" presentes na área do projeto agrícola serem conseqüentemente fragmentadas, o que provoca a disjunção e o isolamento de áreas de vegetação nativa, ou seja, estabelece-se o processo da "fragmentação interna" (Goosem, 1997).

$\mathrm{Na}$ etapa de visita a campo constatou-se que a interferência antrópica na área vem se intensificando, fato este comprovado pelos sinais encontrados: construções de aterro destinado à locomoção de veículos e pessoas; remoção da cobertura vegetal para construção de estradas; presença de gado nas bordas e no interior das “ipucas”, principalmente aquelas próximas à área 
agrícola; evidências de atividades turísticas às margens de rios, lagos, lagoas e córregos, constatadas pela presença de lixo como sacos plásticos, embalagens descartáveis, carvão vegetal, restos de alimentos, pedaços de linhas e anzóis; marcas de fogo nos troncos das árvores; árvores derrubadas e sinais de cortes de madeiras; presença de sementes de espécies invasoras, em geral carreadas por animais dispersores; e sinais de remoção de "ipucas" nas áreas do projeto agrícola.

As "ipucas" são verdadeiros "ninhais", principalmente para a avifauna, e como conseqüência de sua ausência intensifica-se o processo migratório de predadores naturais, desencadeando alterações no equilíbrio do ambiente. Um exemplo a ser citado é o aumento incontrolável de espécies de ratos, que podem provocar danos às áreas cultivadas.

O fogo de ocorrência natural e, ou, criminosa, comum nas regiões de cerrado, é também fato constante e preocupante. Em entrevista com o proprietário da fazenda, soube-se que no último período de secas as queimadas chegaram a atingir níveis altamente prejudiciais ao meio ambiente, sendo as "ipucas" diretamente atingidas. Em visitas a estas, presenciou-se grande quantidade de espécies vegetais mortas ou com sinais de queimadas. Além disto, foram encontrados vários animais mortos e queimados, próximos às "ipucas".

\subsection{2. Área}

A área da propriedade perfaz um total de 8.235,65 ha. Destes, $1.199,34$ ha fazem parte da área do projeto agrícola. As "ipucas" mapeadas somaram um total de 73 fragmentos (Figura 4), e representam uma área de $1.107,36$ ha, ou seja, $13,80 \%$ da propriedade é constituída por "ilhas" formadas predominantemente por espécies arbóreas. Deste total, 13 "ipucas" estão totalmente inseridas na área do projeto, como pode ser observado na Figura 3. Das 73 "ipucas", 41 (56,16\%) possuem áreas de até 5,00 ha. As que apresentaram áreas entre 5,00 e 10,00 ha somaram 15 "ipucas" (20,55\%). Quatro possuem áreas superiores a 100 ha, sendo a "ipuca" 8 a maior, com 246,42 ha. Os valores absolutos, o perímetro e o índice de circularidade de cada "ipuca" estão representados no Quadro 1.

\subsubsection{Perímetro}

O maior perímetro é representado pela "ipuca" 8 (destacada na Figura 4), com $50.700 \mathrm{~m}$. Este fragmento possui parte de seus perímetros inserida na área destinada à agricultura e pastagem plantada, condição que deve ser considerada com atenção especial, uma vez que os problemas ambientais decorrentes das atividades antrópicas são evidentes nessas regiões. Do total de "ipucas" mapeadas, cinco delas $(12,20,37,49$ e 53) apresentaram perímetros inferiores a $500 \mathrm{~m}$, cujo perímetro médio foi de $3.009 \mathrm{~m}$.

\subsubsection{Forma}

As "ipucas" 8 e 50 , com C igual a 0,10 e 0,17 , respectivamente, apresentaram os menores valores relativos à forma. Do total de "ipucas" individualizadas, 12 apresentaram-se arredondadas, com índices entre 0,76 e 1,00. As "ipucas" com valores mais próximos de 1 são: 2,37 , 53 e 55 , os quais equivalem a $0,85,0,83,0,83$ e 0,81 , respectivamente. As "ipucas" 2 e 37 , com tendência à forma circular, estão totalmente inseridas na área do projeto agrícola. Esta forma circular pode ser atribuída aos sucessivos processos de aração e à ocorrência de queimadas. Assim, os fragmentos ficam suscetíveis a essas interferências, principalmente nas bordas, em geral reduzidas anualmente.

Como pôde ser observado, aproximadamente 50\% das "ipucas" apresentaram tendências longilíneas, ou seja, com valores inferiores a 1 (Quadro 2). Entretanto, devese ressaltar que estas se apresentaram com uma alta razão borda/interior e que quanto mais alongada maior será a região de área exposta a efeitos ambientais, resultantes de ações antrópicas.

\subsubsection{Vizinhança}

Foram identificados oito tipos de feições vizinhas às "ipucas", sendo estas: varjão-sujo, varjão-limpo, floresta ciliar, pastagem natural, pastagem plantada, área agrícola, corpos d'água e afloramento rochoso. Do total, seis são sistemas fisionômicos naturais e três resultantes de ações antrópicas. Dentre os diversos elementos considerados para o diagnóstico ambiental de fragmentos florestais, a vizinhança representa um dos mais graves fatores de distúrbio. A Figura 5 apresenta os valores porcentuais do tipo de vizinho para cada "ipuca". Neste contexto, destacam-se aquelas que são completamente inseridas ou que se avizinham com as áreas agrícolas. Estas atividades colocam os fragmentos sujeitos à ação de todos os tipos de perturbações, como uso de defensivos agrícolas; queimadas; afugentamento da fauna silvestre, provocado pela poluição sonora oriunda das máquinas e dos veículos motorizados; presença de lixo; e deposição de embalagens usadas no armazenamento de inseticidas e herbicidas.

R. Árvore, Viç̧osa-MG, v.26, n.3, p.299-309, 2002 


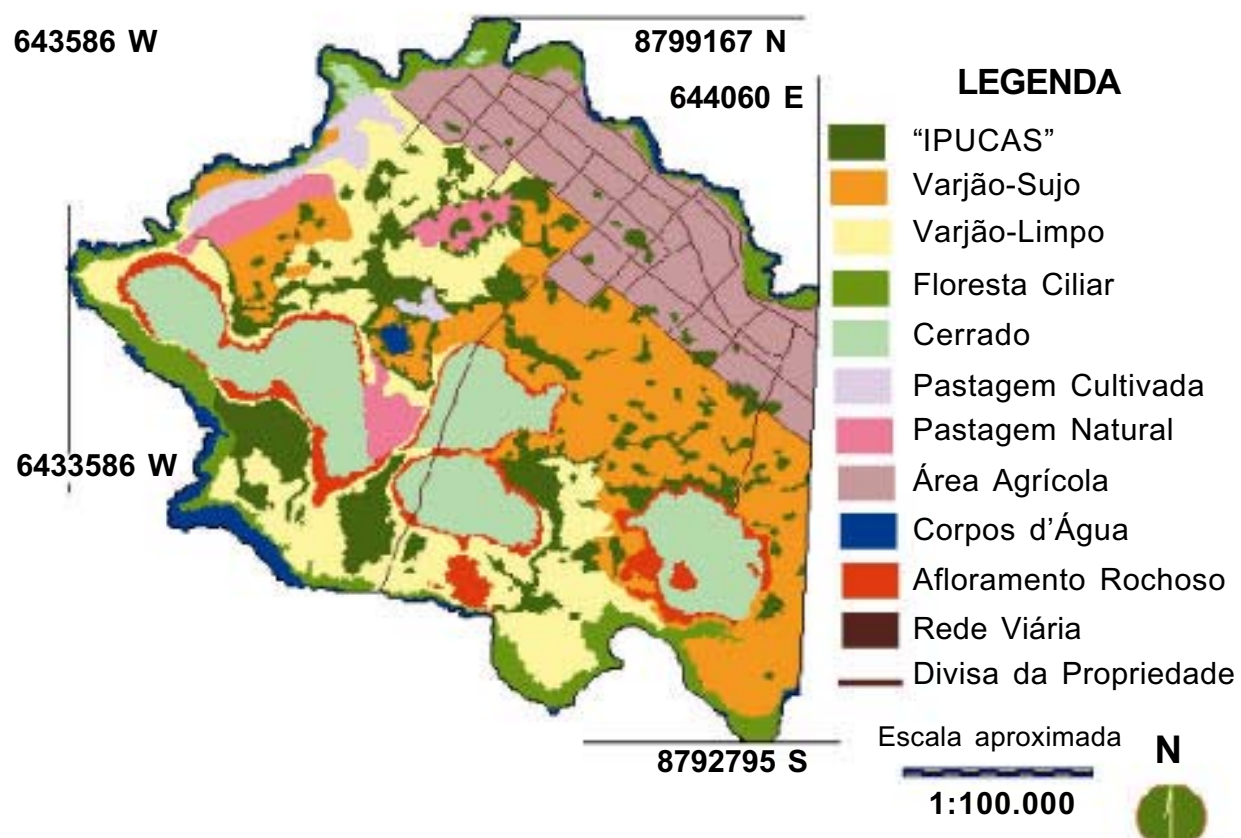

Figura 3 - Mapa de classificação fitofisionômica e uso antrópico da fazenda Lago Verde, município de Lagoa da Confusão-TO. Figure 3 - Classification cover types and anthropic use map, Lagoa da Confusão County-TO.

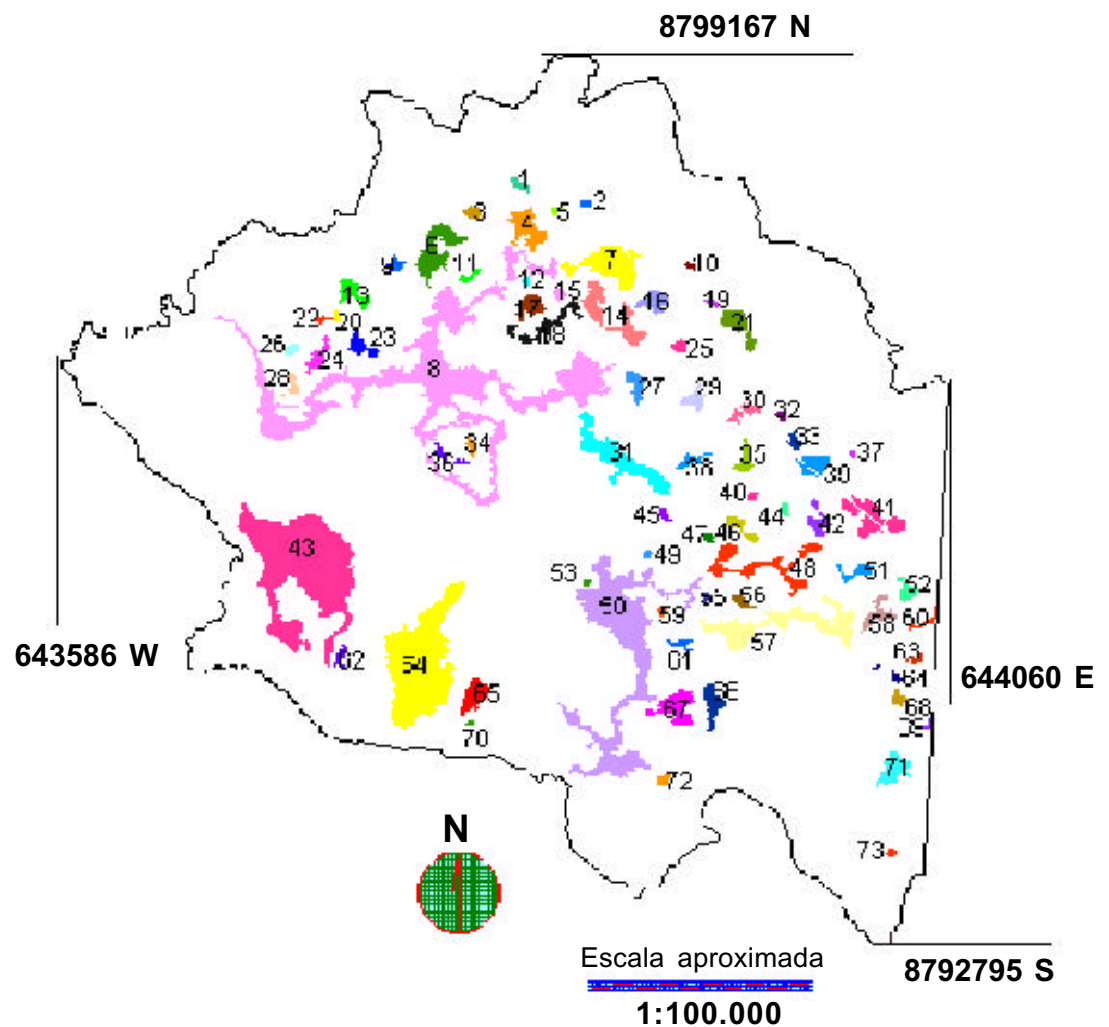

Figura 4 - Mapa de individualização das 73 “ipucas” da fazenda Lago Verde, município de Lagoa da Confusão-TO. Figure 4 - Map showing the 73 "ipuca" natural forests in the Lagoa da Confusão County-TO. 
Diagnóstico Ambiental no Contexto da Paisagem de Fragmentos ...

Quadro 1 - Dados relativos à área, ao perímetro e à forma das "ipucas" da fazenda Lago Verde, município de Lagoa da Confusão-TO

Table 1 - "Ipucas" area, perimeter and shape located in Lago Verde Farm, Lagoa da Confusão-TO

\begin{tabular}{|c|c|c|c|c|c|c|c|}
\hline $\begin{array}{c}\text { "Ipuca" } \\
\left(\mathrm{N}^{\mathrm{o}}\right)\end{array}$ & Área (ha) & Perímetro (m) & $\begin{array}{l}\mathrm{C}^{*} \text { Índice de } \\
\text { Circularidade }\end{array}$ & $\begin{array}{l}\text { "Ipuca" } \\
\left(\mathrm{N}^{\mathrm{o}}\right)\end{array}$ & Área (ha) & Perímetro (m) & $\begin{array}{l}\mathrm{C}^{*} \text { Índice de } \\
\text { Circularidade }\end{array}$ \\
\hline 1 & 2,79 & 1.020 & 0,58 & 37 & 0,99 & 420 & 0,83 \\
\hline 2 & 1,71 & 540 & 0,85 & 38 & 3,69 & 1.560 & 0,43 \\
\hline 3 & 3,33 & 1.080 & 0,59 & 39 & 8,64 & 2.520 & 0,41 \\
\hline 4 & 15,84 & 3.248 & 0,43 & 40 & 1,44 & 540 & 0,78 \\
\hline 5 & 1,35 & 600 & 0,68 & 41 & 19,62 & 5.520 & 0,28 \\
\hline 6 & 22,59 & 4.560 & 0,36 & 42 & 6,75 & 2.280 & 0,40 \\
\hline 7 & 28,62 & 4.620 & 0,41 & 43 & 154,89 & 13.200 & 0,33 \\
\hline 8 & 246,42 & 50.700 & 0,10 & 44 & 1,62 & 600 & 0,75 \\
\hline 9 & 3,33 & 1.020 & 0,63 & 45 & 1,8 & 720 & 0,66 \\
\hline 10 & 1,35 & 600 & 0,68 & 46 & 5,13 & 1.740 & 0,46 \\
\hline 11 & 2,43 & 1.080 & 0,51 & 47 & 1,26 & 600 & 0,66 \\
\hline 12 & 0,9 & 480 & 0,70 & 48 & 25,65 & 7.500 & 0,23 \\
\hline 13 & 8,37 & 2.160 & 0,47 & 49 & 1,08 & 480 & 0,76 \\
\hline 14 & 21,78 & 4.860 & 0,34 & 50 & 124,29 & 22.200 & 0,17 \\
\hline 15 & 2,16 & 720 & 0,72 & 51 & 5,58 & 1.920 & 0,43 \\
\hline 16 & 8,28 & 1.800 & 0,56 & 52 & 4,95 & 1.500 & 0,52 \\
\hline 17 & 8,19 & 1.680 & 0,60 & 53 & 0,99 & 120 & 0,83 \\
\hline 18 & 14,58 & 5.220 & 0,25 & 54 & 108,81 & 8.340 & 0,44 \\
\hline 19 & 1,53 & 660 & 0,66 & 55 & 1,53 & 540 & 0,81 \\
\hline 20 & 1,17 & 480 & 0,79 & 56 & 3,15 & 1.020 & 0,61 \\
\hline 21 & 11,34 & 2.280 & 0,52 & 57 & 46,26 & 9.300 & 0,25 \\
\hline 22 & 1,44 & 720 & 0,59 & 58 & 8,28 & 2.520 & 0,40 \\
\hline 23 & 6,57 & 1.680 & 0,54 & 59 & 1,26 & 540 & 0,73 \\
\hline 24 & 6,30 & 1.980 & 0,44 & 60 & 2,97 & 1.620 & 0,37 \\
\hline 25 & 2,79 & 780 & 0,75 & 61 & 2,79 & 1.320 & 0,44 \\
\hline 26 & 2,16 & 660 & 0,78 & 62 & 3,06 & 1.320 & 0,46 \\
\hline 27 & 7,11 & 1.740 & 0,54 & 63 & 1,89 & 960 & 0,50 \\
\hline 28 & 3,69 & 1.500 & 0,45 & 64 & 3,06 & 1.500 & 0,41 \\
\hline 29 & 5,94 & 1.680 & 0,51 & 65 & 10,44 & 1.980 & 0,57 \\
\hline 30 & 5,49 & 2.040 & 0,40 & 66 & 8,82 & 2.160 & 0,48 \\
\hline 31 & 34,38 & 5.940 & 0,34 & 67 & 15,84 & 3.000 & 0,47 \\
\hline 32 & 1,35 & 660 & 0,62 & 68 & 3,06 & 900 & 0,68 \\
\hline 33 & 2,97 & 1.200 & 0,50 & 69 & 1,17 & 540 & 0,71 \\
\hline 34 & 2,16 & 960 & 0,54 & 70 & 1,17 & 540 & 0,71 \\
\hline 35 & 5,85 & 1.620 & 0,52 & 71 & 11,52 & 2.340 & 0,51 \\
\hline 36 & 4,14 & 2.040 & 0,35 & 72 & 2,16 & 660 & 0,78 \\
\hline$\ldots$ & $\ldots$ & $\ldots$ & $\ldots$ & 73 & 1,35 & 540 & 0,76 \\
\hline
\end{tabular}

*C - índice de circularidade, dado pela raiz quadrada da área da "ipuca" dividida pela área de um circulo de mesmo perímetro. 
Quadro 2 - Dados porcentuais referentes ao fator forma das "ipucas", por classes de ocorrência, na fazenda Lago Verde, Lagoa da Confusão-TO

Table 2 - "Ipucas" shape factor percentage by occurrence classes, located on Lago Verde Farm, Lagoa da ConfusãoTO

\begin{tabular}{|c|c|c|}
\hline \multirow{2}{*}{ Classe de Forma $\left(\mathrm{C}^{*}\right)$} & \multicolumn{2}{|c|}{ "Ipucas" } \\
\cline { 2 - 3 } & Ocorrência & $\%$ \\
\hline $0 \leq 0,25$ & 5 & 6,85 \\
$0,26-\mid 0,50$ & 27 & 36,99 \\
$0,51-\mid 0,75$ & 31 & 42,47 \\
$0,76-\mid 1,00$ & 10 & 13,70 \\
\hline Total & 73 & 100,00 \\
\hline
\end{tabular}

${ }^{*} \mathrm{C}=$ raiz quadrada da área da "ipuca" dividida pela área de um círculo de mesmo perímetro.

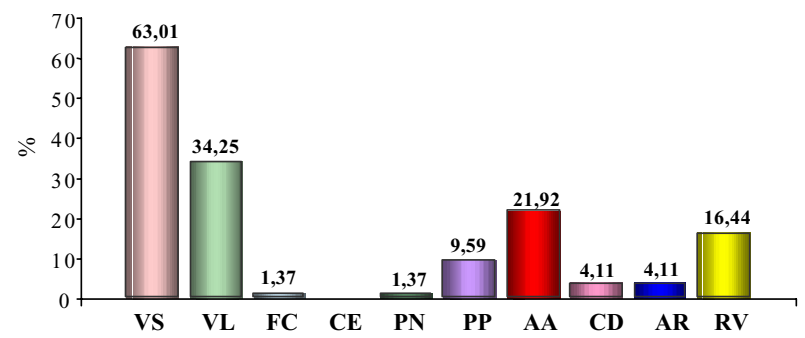

VS - Varjão-sujo, VL - varjão-limpo, FC - floresta ciliar, CE - cerrado, PN - pastagem natural, PP - pastagem plantada, AA - área agrícola, $\mathrm{CD}$ - corpos d'água, $\mathrm{AR}$ - afloramento rochoso e $\mathrm{RV}$ - rede viária.

Figura 5 - Porcentagem do número de "ipucas" que se avizinham aos diferentes tipos de feições fisionômicas ou antrópicas na fazenda Lago Verde, município de Lagoa da Confusão-TO.

Figure 5 - Neighboring types (percentage) in relation to "ipuca” natural forest fragments. Lagoa da Confusão-TO.

Em fragmentos isolados por cercas, estas podem impedir a locomoção de espécies dispersoras, ou ainda impedir a saída do que certamente prejudicaria a vegetação natural. Do mesmo modo, verificou-se em visitas de campo que as "ipucas" que se avizinham às vias de acesso ( $16,44 \%$ do total) estão submetidas a vários tipos de perturbação, dos quais se destacam: depósito de propágulos sexuados e assexuados de espécies invasoras e oportunistas, juntamente ao material usado para a construção do aterro; carreamento do material superficial para o interior da "ipuca", por ocasião das chuvas ou alagamento; deposição excessiva de particulados (poeiras) sobre a vegetação; atropelamento de animais e afugentamento da fauna terrestre; facilidade de acessos às pessoas e animais domésticos.

Tendo em vista que 9,59\% das "ipucas" localizamse em regiões vizinhas às pastagens plantadas, e que essas não possuem cercas divisórias, a presença de bovinos submete os fragmentos a prejuízos em relação aos processos sucessionais e de regeneração da vegetação, devido à quebra de mudas e ao pisoteio. Por outro lado, $97,26 \%$ das "ipucas" têm como vizinhança o varjão-sujo ou limpo, sendo esses ambientes os de melhores condições ambientais, com exceção das regiões mais próximas à sede da fazenda, que pela inexistência de cercas favorecem a entrada de animais, mesmo nos ambientes naturais como cerrado e corpos d'água.

A adjacência com os corpos d'água (lagos e lagoas) totalizou $4,11 \%$ das "ipucas" mapeadas. As áreas de cerrado não se avizinham com as "ipucas", em conseqüência da proximidade em $30 \mathrm{~m}$ estabelecida neste estudo. Entretanto vale ressaltar que, em geral, os fragmentos próximos a esse tipo de fisionomia representam uma alta porosidade às espécies da fauna silvestre. Ao comparar este tipo de feição circunvizinha com aquelas resultantes de atividades antropogênicas como pastagens plantadas, áreas agrícolas e vias de acesso, estas representam uma redução na porosidade para a fauna silvestre.

\section{CONCLUSÕES}

Diante dos procedimentos contemplados nas várias etapas deste estudo, foram obtidas as seguintes conclusões:

- as características mais evidentes em relação aos aspectos fisionômico-ecológicos das "ipucas" são: 1) apresentam-se em forma de "dolinas", ou seja, pequenas depressões resultantes do processo de perda de água e ganho de matéria orgânica, nos períodos de seca e alagamento, respectivamente; 2) os solos são pouco profundos, com camada superficial aparentemente rica em matéria orgânica, 3) o predomínio de espécies arbóreas é representado pelo agrupamento de algumas delas, como o landi, a canjerana e o carvoeiro (verificados nas entrevistas com moradores locais); e 4) o sub-bosque, presente nas bordas, tende a desaparecer à medida que se adentra na "ipuca"; 
- a classificação fisionômica da área apresentou 11 classes: "ipucas: varjão-sujo, varjão-limpo, floresta ciliar, cerrado, pastagem plantada, área agrícola, corpos d'água, afloramento rochoso e rede viária. A área total da propriedade é de $8.235,65$ ha, dos quais $1.107,36$ ha $(13,45 \%)$ são cobertos pelas "ipucas" e cerca de $2.500,00$ ha $(10,64) \%$ ), com altos níveis de antropização;

- a maioria das "ipucas" (56,16\%) possui áreas de até 5,00 ha, tendo a "ipuca" 8 apresentado maior área ( $246,42 \mathrm{ha})$ e outras quatro apresentado áreas acima de 100,00 ha;

- aproximadamente $50 \%$ das "ipucas" possuem formas alongadas, estando sob intenso efeito de borda. As "ipucas" 2, 37, 53 e 55 foram as que apresentaram C próximos de 1 com melhores condições ambientais, especialmente nas bordas, onde os efeitos são minimizados devido à forma arredondada;

- foram identificadas nove feições circunvizinhas às "ipucas". Destas, seis são ambientes naturais e as demais são resultantes de ações antrópicas, como pastagem plantada, área agrícola e rede viária. O tipo de vizinhança é um fator de distúrbio ambiental, sendo as atividades agropecuárias as que oferecem maiores possibilidades de desequilíbrios ambientais. A vizinhança com o varjão-sujo e o varjão-limpo é a mais expressiva na área de estudo, o que é um fator positivo, uma vez que esta feição é uma fisionomia ecologicamente compatível com o equilíbrio dos aspectos físicos e bióticos.

\section{REFERÊNCIAS BIBLIOGRÁFICAS}

BRASIL. Instituto Brasileiro de Desenvolvimento Florestal - IBDF, Fundação Brasielira para a Conservação da Natureza. Plano de Manejo: Parque Nacional do Araguaia. Brasília: 1981a. 103 p.
BRASIL. Ministério das Minas e Energia. Secretaria Geral. Projeto RADAMBRASIL. Folha SC. 22. Tocantins: Geologia, geomorfologia, pedologia, vegetação e uso potencial da terra. Rio de Janeiro: 1981b. 524 p.

BRASIL. Ministério do Meio Ambiente e da Amazônia Legal. Instituto Brasileiro do Meio Ambiente e dos Recursos Naturais Renováveis - IBAMA. Plano de Ação Emergencial para o Parque Nacional do Araguaia. Brasília: 1994. p. 56 (Documento de informações básicas).

GOOSEM, M. Internal fragmentation: the effects of roads, highways and powerline clearings on movements and mortality of rainforest vertebrates. In: LAURANCE, W. F.; BIERREGGARD JÚNIOR, R. O. Tropical forest remnants: ecology, management, and conservation of fragmented communities. Chicago: University of Chicago, 1997. p. 241-255.

MILESKI, E. Aspecto da vegetação e do ecossistema da Ilha do bananal. Mapa fitoecológico e indicadores da pressão antrópica. Brasília: Gráfica da Secretária de Assuntos Estratégicos, 1994. 104 p.

SAUNDERS, D. A.; HOBBS, R. J.; MARGULES, C. R. Biological consequences of ecosystem fragmentation: a review. Conservation Biology, v. 5, n. 1, p. 18-35, 1991.

TOCANTINS. Companhia de Desenvolvimento do Estado do Tocantins, UNITINS. Universidade do Tocantins. Estudo de Impacto Ambiental EIA - RIMA. Projeto Javaés: sub-projeto Lagoa. 1996. 2 v. Paginação irregular.

VALÉRIO FILHO, M. Gerenciamento de bacias hidrográficas com aplicação de técnicas de geoprocessamento. In: TAUK - TORMELO, S. M. Análise ambiental: estratégias e ações. Rio Claro: Universidade Estadual de São Paulo, 1995. p. 135-140.

VIANA, V. M. Biologia e manejo de fragmentos florestais naturais. In: CONGRESSO FLORESTAL BRASILEIRO, 6., 1990, Campos do Jordão. Anais... Campos do Jordão: SBS/SBEF, 1990. p.113-118. (Trabalhos convidados) 